\title{
100 https://doi.org/10.26552/com.C.2003.3.91-98
}

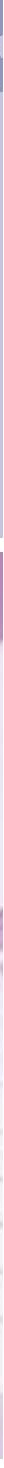

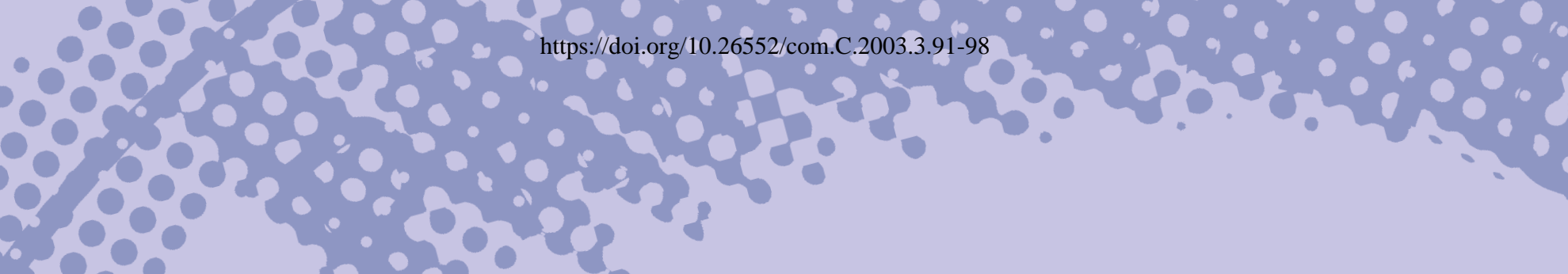

FACULTY OF SCIENCE $\because \because \because \because \because \because \because \cdots$ $\because \because \because \because \because \because \because \because \because \because \because 0 \%$

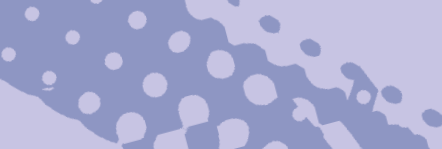

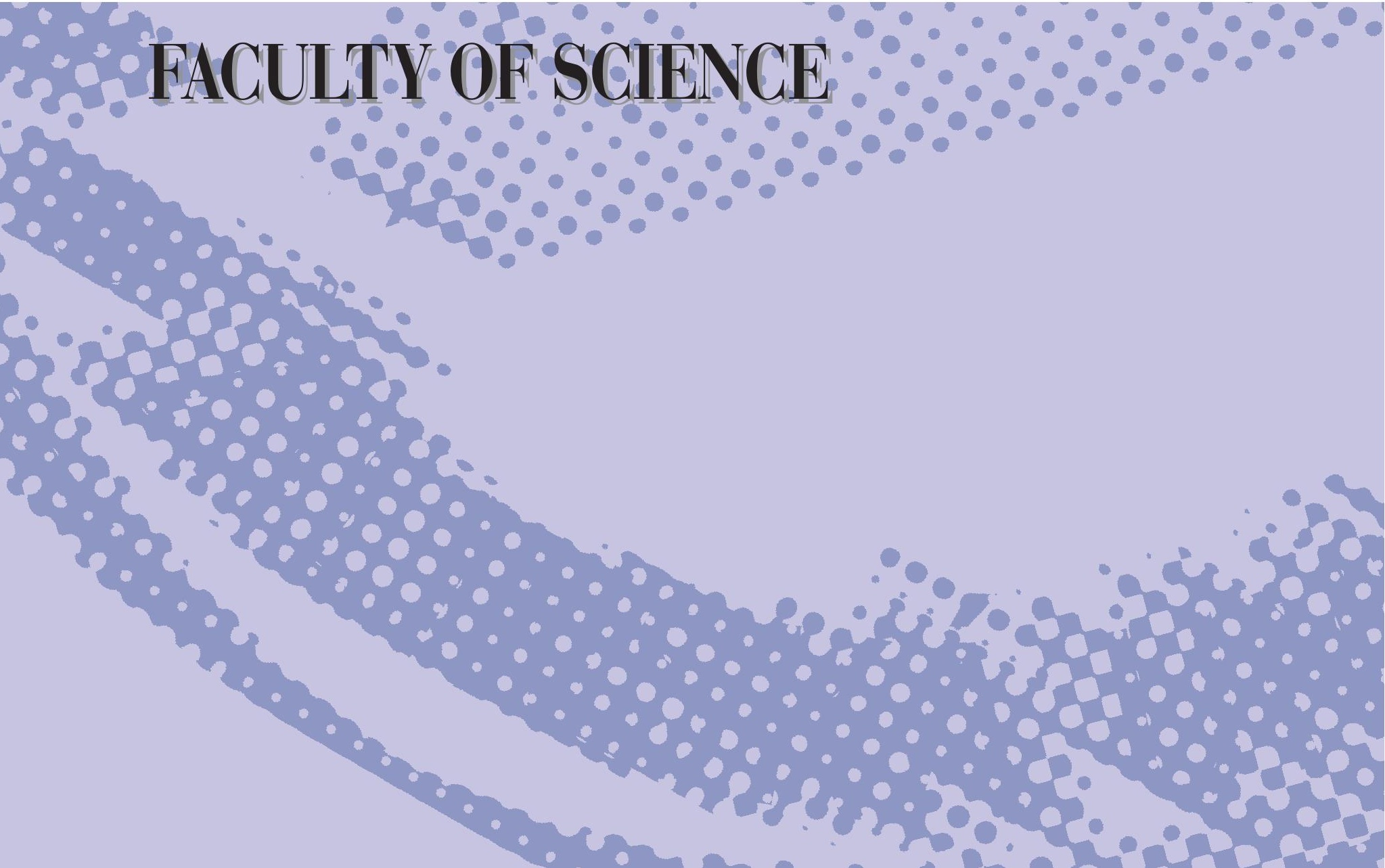




\section{FACULTY OF SCIENCE}

Knowledge is but the struggle for knowledge. And we are always equally far from and equally near it.

(Ramón Sender)

Hurbanova 15, 01026 Žilina
Dean:
Assoc. Prof. RNDr. Miroslava Růžičková, CSc.
E-mail: ruzickova@fpv.utc.sk
Vice-dean for education:
PhDr. Radoslava Turská, CSc.
E-mail: turska@fpv.utc.sk
Vice-dean for science, research and foreign relations Socrates
faculty coordinator
PhDr. Anna Hlavňová, CSc.
E-mail: hlavnova@fpv.utc.sk
Vice-dean for development
Prof. Ing. Ivo Čáp, CSc.
E-mail: icap@nic.utc.sk

\section{General information}

The history of the Faculty of Science is relatively short - the Faculty was established in August 1998 with an objective to complete the former mostly technically oriented education with courses in humanities. Although the first departments of the newly created Faculty were departments of mathematics, other departments were gradually established and currently there is a wide range of subjects that can be studied in bachelor's or master's programs and one subject also in a postgraduate program.

Although there are several universities in Slovakia offering full degree programs in English Language and Literature and/or concentrating on training teachers there is a permanent shortage of qualified teachers of English. To improve the situation the management of the Faculty decided to design new five-year degree programs concentrating on training teachers of English and another subject, as for example, mathematics/information science/music/religious studies. Curricula and courses were thoroughly redesigned to meet new requirements and incorporate the experience of the rest of the world. The courses allow for the training of either primary school or secondary school teachers. The courses offered by the Faculty are diverse.

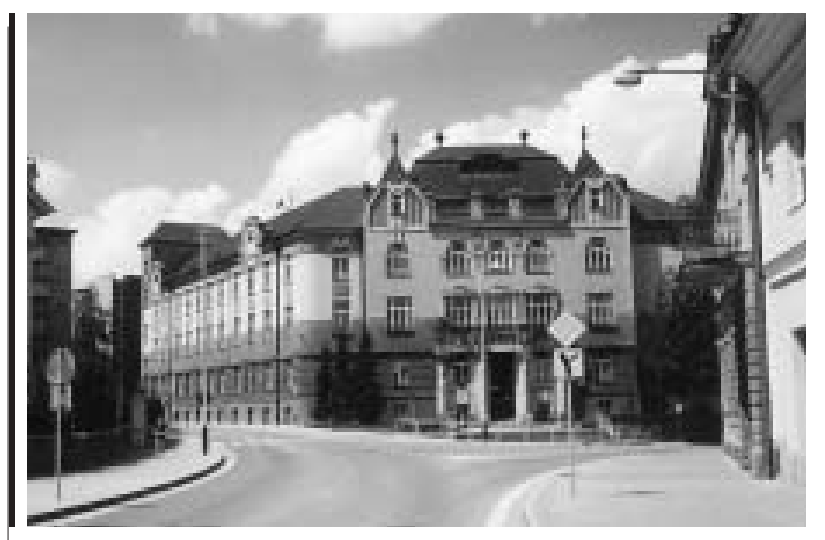

Bachelor's degree programs: Mediamatics

Master's degree programs: Applied mathematics Teacher Training (English in combi-
nation with physics/music/information
science/mathematics/religious science)

Postgraduate degree program: Applied mathematics

Apart from this diversity the Faculty promotes a relaxed and friendly atmosphere that facilitates learning and experience.

The faculty is located in the very heart of the town. It is a place where undergraduate education is a lively, flourishing enterprise which is given the highest priority by the Faculty community. The courses are designed to meet the needs of schools in the $21^{\text {st }}$ century. Relaxed and friendly atmosphere makes the Faculty an ideal place to study. The faculty staff help students realize educational and social needs and develop skills that are at present in great demand.

\section{Departments of the Faculty}

The faculty consists of the following departments:

- The department of mathematical analysis and applied mathematics,

- The department of algebra, geometry and didactics of mathematics,

- The department of mathematics,

- The department of physical sciences,

- The department of pedagogy and psychology,

- The department of humanities and social sciences

- The department of English language and literature,

- The department of foreign languages.

From the beginning of its existence the Faculty has endeavored to create an integrated partnership model with very strong theory and practical links. It is generally accepted that mathematics and, particularly, applied mathematics is an expanding area. Knowledge of the latest ideas, techniques and computational approaches is essential for today's mathematicians, be they involved in industry, commerce or research.

The courses offered by the all three departments of mathematics provide detailed knowledge and skills in certain key areas of modern mathematics including data analysis, numerical analysis, mathemati- 
cal statistics, partial differential equations, linear algebra, analytical geometry, computer geometry, didactics of mathematics, etc. Appropriate attention is paid to statistics with the objective to train graduates to develop and apply statistical techniques, probability, mathematical statistics, linear models and computer-oriented statistical methods. Students are expected to achieve a basic knowledge of statistics and research methods. There are also courses covering most areas of computer science, for example, computer architecture, data base and information systems, logic and computation, theory of computation, parallel algorithms, etc.

Whenever possible, theory that is presented is matched with an appropriate real-world application, to enable the learner to appreciate the scope of the new ideas being encountered.

The aim of the courses designed to train teachers is to develop knowledgeable, enthusiastic and forward-looking mathematics teachers, who are confident in their ability to learn and grow professionally.

The Department of Humanities and Social Sciences together with the Department of Pedagogy and Psychology offer courses in philosophy, general and development psychology, history of culture and arts, theory of communication, political sciences, sociology, school management, etc. Within courses in philosophy the students are required to gain and display thorough knowledge of the history and problems of philosophy and considerable analytical skills. In the area of political sciences the curriculum combines theoretical and functional courses in a broad range of topics.

The courses in education strongly emphasize an interdisciplinary approach to professional training in education - linguistic and psychological perspectives are especially represented.

In courses devoted to mediamatics the students are trained to apply the theories and methods of social science to problems in interpersonal and mass communications, visual communication and cultural analysis and media management and regulation.

The music section aims to provide a congenial and friendly environment in which both staff and students share jointly in the study of music, both practical and theoretical. Each student is encouraged to develop his or her particular interests and abilities to the utmost. Music can be taken as a single course (performing on the musical instrument) or in conjunction with English. Teaching is by means of lectures, small-group seminars, and individual supervision.

The graduate programs of the section of religious studies draw widely on religious traditions, philosophy of religion, religious ethics.

English has become the uncontested number one foreign language in popularity and prestige in Slovakia although historically the country belonged to the German and Hungarian cultural area and German used to be the most widely taught and spoken foreign language. Later, due to political situation, Russian was a compulsory foreign language in all types of primary and secondary schools and also in institutions of higher learning. Towards the end of the $20^{\text {th }}$ century study of English reinvigorated and its popularity has only increased in recent years.
When the Faculty decided to launch programs focusing on training teachers of English it was necessary to set up the Department of English Language and Literature alongside with the existing Department of Foreign Languages, which has been an integral part of the University since its very beginning, i. e. for 50 years. The Department of Foreign Languages provides courses in languages for specific purposes for students of all the faculties. Students can choose from the following languages: English, German, Russian, Spanish, French or Italian. The newly set up Department of English Language and Literature offers students who want to be teachers a flexible five-year program that combines broad coverage of both English and American literature and linguistics, which are well balanced. The MA programs for teachers of English (+ other subject), cover practical language instruction (analytical reading, writing, grammar, phonetics), linguistics (theoretical grammar, language history, lexicology, semantics, pragmatics), literature (both English and American) and cultural studies (British and American).

The aim of linguistics is to establish a thorough grounding in the study of language, and to develop the student's own ability to weigh up issues and analyze problems. The students explore the role of language as a means of communication in society, the production and transmission of speech, the basic workings of the sound system, the grammatical rules and the negation of meaning in language, and how languages change and compare with one another.

All courses are taught in English and thus students continue to develop their English skills through their university years.

Teachers from the two departments work both on questions of applied linguistics and language teaching methodology. They also have worked on questions of language and literature with applications in the language teaching process. Although up to now, research has been of secondary importance some significant work has been done on corpus linguistics and lexicography and translations.

These results have started to prove the potential of the Faculty specialists of foreign languages in the eyes of the University academic community which has traditionally regarded foreign philologists as mere language teachers.

The Department of English Language and Literature currently offers in-service training for practicing teachers from Slovak bilingual secondary schools who are to teach special subjects, e.g. history, geography, mathematics, etc. in English.

The Faculty has signed several bilateral agreements to recognize the grades awarded by other institutions enabling both students and staff to move between universities (e.g. within the framework of Socrates program.

\section{Computing services}

Computing facilities are provided at all sites in an open access computer laboratory to support development of student-centred learning and teaching. The faculty workplaces are fully networked and connected to the Internet.

\section{Significant activities of the Faculty staff}

From a wide range of diverse activities carried out by the faculty teachers and research workers the following projects are worth mentioning: 


\section{LOCAL SOCIETY INITIATIVE POLYLOGOS}

E-mail: labudova@fpv.utc.sk; pavolbartolomej@pobox.sk

Three things are extremely hard: steel, a diamond and to know one's self.

(Benjamin Franklin)

\section{Science, Religion, Pfilasopdie:} A searclf for cummunication and rolerance

\section{Description and objectives of the initiative}

Polylogos group was established in 2001 as a local social network of academics with the aim to explain fundamental categories and subjects of individual disciplines as a platform of effective communication and tolerance. The dialogue and explanation of these categories is considered to be an inevitable condition for transfer of knowledge in the range of individual academic disciplines in Slovakia. To accomplish these objectives, the group regularly delivers workshops; lectures and seminars and on-line conferences, organizes meetings with invited specialists of particular scientific areas (science, formal science, philosophy, theology).

\section{LEONARD0 DA VINCI II Project: Deutsch im Maschinenbau (DEUMA) CZ/01/B/F/LA - 134057}

\section{Description of the project}

The project Deutsch im Maschinenbau (DEUMA) was approved by the European Commission in 2001 within the framework of LEONARDO DA VINCI II. Program. Its objective is to design a multimedia textbook of German for specific purposes. Participants in the project are from eleven different organizations from five countries. Five of the participants are from European member countries.

The DEUMA textbook is processed by means of multimedia software which was designed at the University of Tübingen that is also a partner of the project. The software is called Telos Language Partner and consists of preprogrammed multimedia patterns.

The textbook will cover nine topics focusing on mechanica engineering in a wider professional context so that the book can be used in a wider spectrum of technically oriented schools. The textbook will be in two languages: in a target and mother language (German - Czech; German - French; German - Slovak). The final version will be provided in two versions: as $\mathrm{CD}$ and on the web.

The main domains agreed upon by experts after endless and numerous discussions are as follows:

- Mathematics;

- Physics, mechanics

- Materials,

- Connecting elements,

- Parts of machines - bearings,

- Parts of machines - gearboxes,

- Parts of machines - pistons and cylinders,

- Tools, apparatus, instruments,

- Interpretation of technical drawings. 
Each domain is further divided into a number of modules in which the main topic is presented in detail. Let us take the domain of Mathematics as an example:

- Module 1 - Sets of numbers.

- Module 2 - Calculation with natural numbers.

- Module 3 - Equations.

- Module 4 - Basic geometric vocabulary: point, straight line, halfline, line segment.

- Module 5 - Triangles, quadrangles, circles.

- Module 6 - Geometric bodies, cube, right parallelepided, prism.

- Module 7 - Cone, tapered cone, cylinder, pyramid, sphere.

Each module contains:

- Introductory text with a video,
- Listening/reading comprehension exercises,

- Exercises to fix vocabulary,

- Grammatical exercises, etc.

Objectives of the project

- To provide a multimedia textbook of professional German;

- To combine classical foreign language teaching and learning with new technologies; thus promoting individual learning

- To support tele-tutoring as the next step in the above process,

- To widen, deepen and foster linguistic competences of Czech, French and Slovak learners using the above textbook thus improving their flexibility and better position in the European labor market.

\section{THE MECHANISM OF NEGATIVE CORONA DISCHARGE IN ELECTRONEGATIVE GASSES}

\section{Description and objective of the project}

Electronegative gases as SF6 and mixture N2+SF6, are widely used in many industrial devices, such as circuit breakers or gases insulating systems. The transmission from negative corona discharge to breakdown in these systems is unwelcome and elimination of this process depends on the understanding of the mechanism of

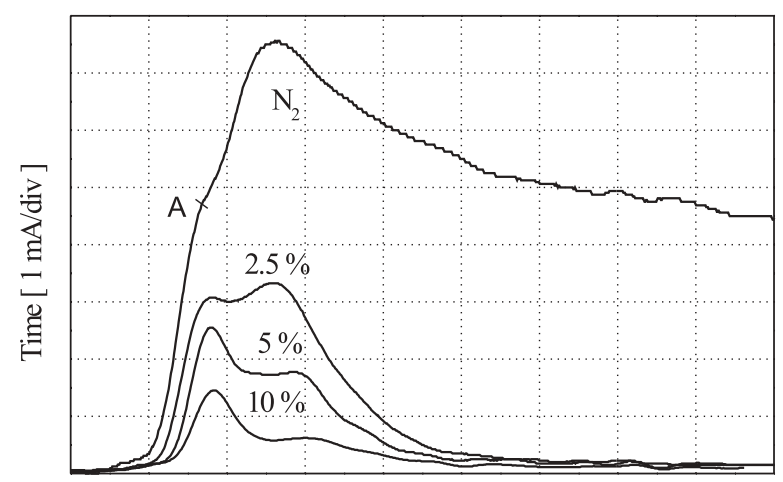

Time [ $2 \mathrm{~ns} / \mathrm{div}$ ]

Fig. 1. Current pulse waveforms taken for various $S F_{6}$ admixtures at a gap voltage value $5250 \mathrm{~V}$ and pressure $50 \mathrm{kPa}$

(distance point-to-plane $12 \mathrm{~mm}$ a radius of the point $0.1 \mathrm{~mm}$ ) the initial stage of discharge. The initial stage of negative corona discharge is in the regime of Trichel pulses. Trichel mechanism presents wide and evident formation of cathode region at high pressure by streamer mechanism.

According to the streamer-based theory the stepped pulse leading edge, current pulses in $N_{2}$ and its mixture with low contents of $S F_{6}$ (Fig. 1), forms as follows: The initial current rises to the step (denoted by A) is due to a Towsend ionization mechanism fed by cathode secondary process $\left(\gamma_{p}-\right.$ emission). After decay the current rises due to the rapidly shrinking cathode fall region, the current begins to rise again because of the development of cathode-direct streamer-like ionization wave. The pulse maximum is attained just as the streamer reaches the cathode. Next quick current fall in mixture $N_{2}+S F_{6}$ is due to negative space charge.

The above result interpreted in terms of streamer-based hypothesis suggests that the effect of adding $>10 \% \mathrm{SF}_{6}$ to $\mathrm{N}_{2}$ was primarily to quench the positive streamer ionization processes, while the effect of the Towsend multiavalanche ionization process was much less pronounced. One may therefore speculates that the strong streamer quenching in $N_{2}-S F_{6}$ mixture has a very efficient corona stabilization effect. The effect of field emission on cathode graphite coating is important at pressure $>40 \mathrm{kPa}$. 


\section{THERMODYNAMIC STUDIES OF LOW DIMENSIONAL ISING MAGNETS}

E-mail: blazek@fpv.utc.sk

We cooperate with the Department of Experimental Physics, Faculty of Science, University of P.J.Šafárik in Košice on studies of dipolar magnets. Our investigations have been focused on the $\mathrm{KEr}\left(\mathrm{MoO}_{4}\right)_{2}$ compound as an example of rare earth dimolybdates which represent dipolar magnets with a layered crystal structure. Previous thermodynamic studies of $\mathrm{KEr}\left(\mathrm{MoO}_{4}\right)_{2}$ in zero magnetic field $B_{0}$ have revealed that below the temperature of $2.5 \mathrm{~K}$ the model converges to the 2 dimensional Ising model with effective spin of $1 / 2$. A phase transition into the antiferromagnetic ordered state has been observed at Neel temperature of $0.955 \pm 0.005 \mathrm{~K}$. The analysis of specific heat data measured in the paramagnetic region in applied magnetic field parallel to an easy axis revealed deviations from the theoretical models. The discrepancies might be ascribed to the predominantly dipolar nature of magnetic correlations. On top of it, the heat capacity depends on the shape of the sample. In the figure there are developments of the heat capacity for four different samples, calculated at the temperature of $2.5 \mathrm{~K}$. The shapes of samples are represented by their demagnetising factors $\mathrm{N}$.

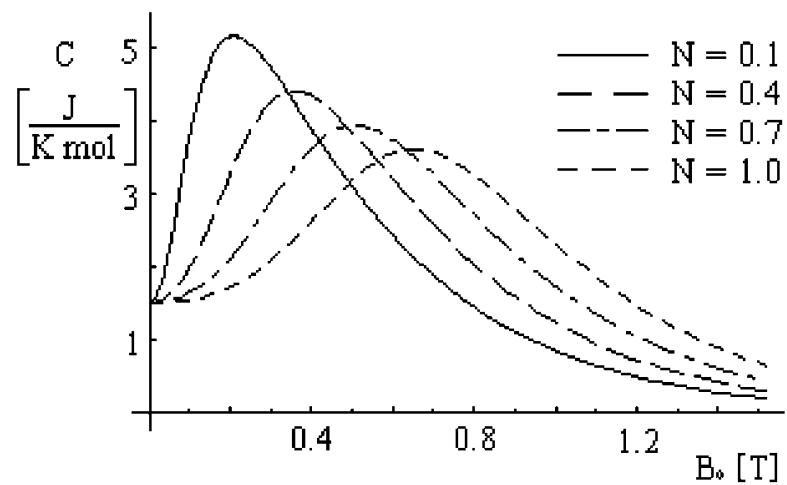

This research was supported by the Slovak Ministry of Education Grant No. 1/7473/20.

\section{IS LANGUAGE THE FINAL BARRIER IN A SHRINKING WORLD? Project UK/00/B/F/LA/129-019

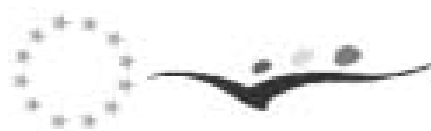 \\ Leonardo Emergency $/ / 2$ \\ Trans Europe Emergency Services Language Training Project}

E-mail: hlavnova@fpv.utc.sk, vladimir_hlavna@kkvmz.utc.sk

\section{Project objective}

Recent international search and rescue operations have presented major difficulties in dialogue, information collation and technical understanding. This has caused operational difficulties and has emphasized the need for closer cooperation between potential countries.

How do emergency services improve cross-border support to emergency incidents/national disasters and ultimately assist in the overall mobility of fire and rescue expertise? One way is by the development of language training within the emergency services.

Under the Leonardo da Vinci vocational training policy, Essex County Fire and Rescue Service, UK, together with six partner organizations, have been developing an innovative language training project known as Leonardo Emergency 112. 

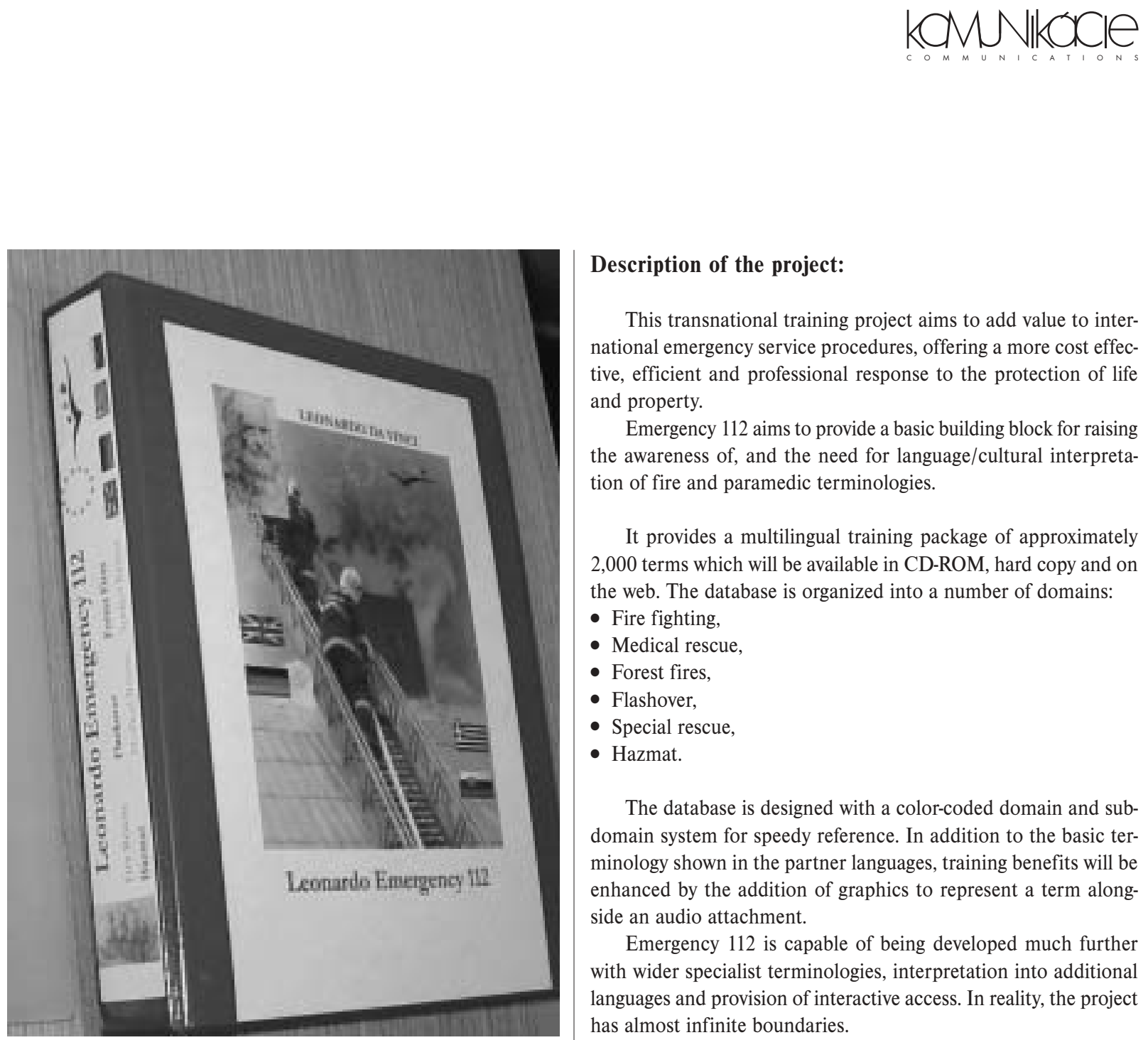

\section{Description of the project:}

This transnational training project aims to add value to international emergency service procedures, offering a more cost effective, efficient and professional response to the protection of life and property.

Emergency 112 aims to provide a basic building block for raising the awareness of, and the need for language/cultural interpretation of fire and paramedic terminologies.

It provides a multilingual training package of approximately 2,000 terms which will be available in CD-ROM, hard copy and on the web. The database is organized into a number of domains:

- Fire fighting,

- Medical rescue,

- Forest fires,

- Flashover,

- Special rescue,

- Hazmat.

The database is designed with a color-coded domain and subdomain system for speedy reference. In addition to the basic terminology shown in the partner languages, training benefits will be enhanced by the addition of graphics to represent a term alongside an audio attachment.

Emergency 112 is capable of being developed much further with wider specialist terminologies, interpretation into additional languages and provision of interactive access. In reality, the project has almost infinite boundaries.

\section{SIGNIFICANT RESULTS OF RESEARCH IN THE FIELD OF MATHEMATICS}

E-mail: ruzickova@fpv.utc.sk

In the beginning of our presentation we mentioned that the first departments of the Faculty of Science founded five years ago were two departments of mathematics. The original staff, who had worked at other faculties of the University, were gradually joined either by fresh graduates from various Slovak universities or by experienced and enthusiastic colleagues from other centers of mathematical research and education. At present the Faculty has three departments of mathematics and covers a wide range of mathematical disciplines thus representing a great potential of research workers. At the Faculty there are good conditions for the building of good research teams. The center of scientific activity is basic research whose results have been presented in numerous interna- tional conferences and published in recognized professional journals.

Scientific and research activities in the departments of mathematics are diverse. The research in the field of functional differential equations and their applications follows the path marked by a reputable research school established by prof. RNDr. Pavol Marušiak, DrSc. The asymptotic and oscillatory properties of solutions of logistic differential equations with delay argument, neutral equations and systems, and singular differential systems are investigated. Oscillatory properties of functional integro-differential equations and their applications in mathematical models are also 
studied. One of numerous important results of this research is the monograph written by P. Marušiak and R. Olach: Functional differential equations. At present, this research is supported by two grant projects.

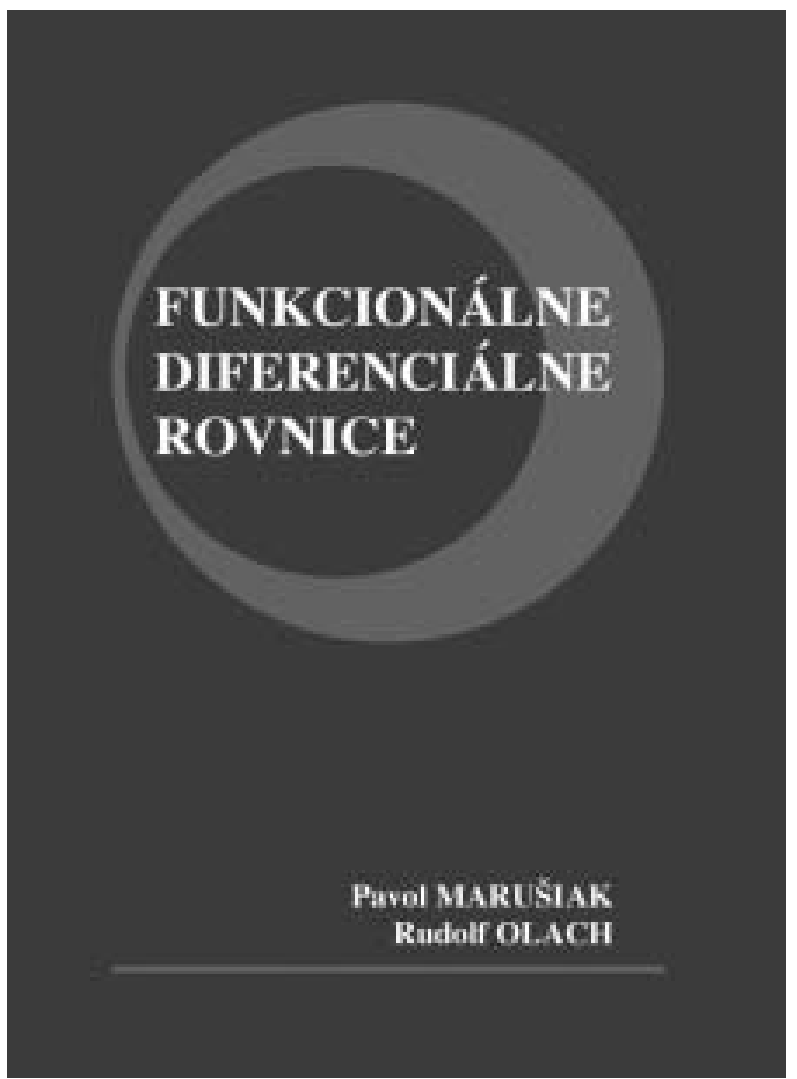

Research in the field of applied mathematics deals with investigation of properties of logic models using the veracity coefficients. The methods of nonstandard analysis are used to join the process of logic. Functional and harmonic analysis is applied in works dealing with mathematical acoustics and also with special functions and orthogonal polynomials. Some researchers deal with numerical mathematics, especially with solution of partial differential equations using the mesh-less methods, and with their practical applications in the problems of vibrations of mechanical systems and in quantum physics.

Projects based on and supporting scientific and research activities of the staff:

- VEGA 1/5189/98 Functional spaces and their applications for solving nonlinear problems for partial differential equations (doc. RNDr. Ondrej Kováčik, CSc.)

- VEGA 1/5254/98 Oscillatory theory of ordinary and functional differential equations (prof. RNDr. Pavol Marušiak, DrSc.)

- VEGA 1/8055/01 Functional differential equations and their applications (doc. RNDr. Rudolf Olach, CSc.)

- VEGA 1/0026/03 Qualitative properties of functional differential and difference equations (prof. RNDr. Josef Diblík, DrSc.)

- International VTS project No. 22(025)/2000 Qualitative properties of solutions of functional differential equations and their applications.

(doc. RNDr. Miroslava Růžičková, CSc.)

- International grant project SAV - CNR

Integration in vector spaces equipped with additional structures (2001 - 2003)

(doc. RNDr. Ján Haluška, CSc.). 